\title{
WEAR AND MICROHARDNESS OF THREE DIFFERENT TYPES OF CAD/CAM CERAMIC MATERIALS
}

\author{
Shereen Kotb Salem*
}

\begin{abstract}
Objective: Wear and microhardness of three different types of CAD/CAM ceramics against enamel as an occlusal antagonist were studied. Also, microhardness was evaluated.

Materials and Methods: The three tested ceramics were: Vita Enamic (polymer-infiltrated ceramic), IPS e.max CAD (lithium disilicate ceramic) and Celtra Duo (Zirconia reinforced lithium silicate ceramic). The occlusal antagonists were extracted teeth. Thirty samples were constructed divided into 3 groups according to the type of ceramic used (10 samples each). Then each group was subdivided into 2 subgroups ( 5 samples each), The first subgroups underwent a microhardness test while the other subgroups were first weighed then subjected to wear test and finally re-weighed again before being subjected to microhardness test.
\end{abstract}

Results: The results showed a significant difference in weight loss due to wear between Vita Enamic and both IPS e.max CAD and Celtra Duo. There was also a significant difference for the antagonist tooth structure as regard both weight and height loss between Vita Enamic and both IPS e.max CAD and Celtra Duo. Microhardness results showed a significant difference between Vita Enamic and both IPS e.max CAD and Celtra Duo as regard microhardness without and after wear. For all the tested ceramics, there was no significant difference as regard microhardness without and after wear test. Also, there was no significant difference as regard wear and microhardness between IPS e.max CAD and Celtra Duo.

Conclusions: Vita Enamic showed the worst wear behavior and the least abrasiveness to enamel while, IPS e.max CAD and Celtra Duo showed comparable wear behavior and abrasiveness to enamel. Also, ceramic microhardness was not affected by wear for the three tested ceramics.

KEY WORDS: Polymer-infiltrated ceramic, Lithium disilicate ceramic, Zirconia reinforced lithium silicate ceramic, Wear, Microhardness.

\footnotetext{
*Lecturer of Fixed Prosthodontics. Faculty of Dentistry, October 6 University
} 


\section{INTRODUCTION}

Wear, according to the engineering dictionary is defined as "Undesired deterioration of a component by removal of a material from its surface."(1) It is also defined as "loss of material resulting from removal and relocation of materials through the contact of two or more materials." ${ }^{(2)}$ Mair et al $\mathbf{( 1 9 9 6 )}^{(3)}$, and Hahnel et al (2011) ${ }^{(4)}$, defined wear as progressive surface loss of a material caused by relative motion .

Many environmental factors as well as material properties affect the wear property. Environmental factors include sliding surfaces interaction, microscopic contact and different combination of materials. Material properties like phases, inclusions, crystal orientation and inhomogeneity affect the material wear. Abrasive wear occurs when a harder material is contacting or sliding over a softer one. Materials having hard, smooth surfaces are more wear resistant. Also, flushing away the abraded particles makes it two body instead of three body abrasion. Sliding action accelerates as well corrosive wear. Surface fatigue wear occurs as the free particles (particles broken off under cyclic loading) contact with the surface causing highly localized stresses producing surface and subsurface cracks. ${ }^{(2)}$

Although dental physiologic wear is a natural, inevitable process, yet excessive tooth wear due to presence of dental restorations in the aggressive oral environment is usually undesirable and needs to be controlled by restorations' finishing and polishing. ${ }^{(5)}$ Oral environment is a unique, dynamic tribological system consisting of four elements: teeth and /or restorative materials, food representing a solid element, saliva acting as lubricant and air. ${ }^{(6)}$ Tribology is defined as "the science and technology of interacting surfaces in relative motion". It studies friction, lubrication and wear. (7) Understanding friction and wear behavior of human teeth against available restorative materials is crucial for preserving normal masticatory function and occlusal harmony. Severe wear causes; tooth height loss, change in occlusal anatomy, hypo-occlusion, change in vertical dimension of occlusion, temporomandibular joint pain, impaired function, functional path alteration, anterior guidance and esthetic loss that indicates complex restorative treatment. ${ }^{(8-11)}$ On the other hand, restoration wear creates micro-cracks and flaws that may result in compromised esthetics, masticatory function impairment, sensitivity, secondary caries and systemic effects due to ingestion of the wear products. ${ }^{(11)}$

Ceramics wear and their abrasiveness against enamel structure is a real concern for clinicians making proper ceramic selection very critical. Researchers recommend that the restorative material should have a compatible wear rate with that of natural tooth enamel. ${ }^{(12,13)}$ Enamel-ceramic wear can be abrasive, fatigue and corrosive. ${ }^{(3)}$

In dentistry hardness of a material is a highly significant property as it allocates its abrasiveness. It is a measure of the resistance to permanent surface indentation or penetration. ${ }^{(14)}$ Dental literature shows a great controversy about the effect of material hardness on its wear resistance as well as its abrasiveness to the opposing. Some researchers reported no relation while others drew the attention to that there is a relation between hardness and the amount of wear as one of multiple factors that affect material wear, that's why a direct relation between hardness and wear is not always achievable..$^{3,15-17)}$

Development of less abrasive aesthetic ceramic materials to minimise enamel wear is one of ceramic manufacturers' goals. ${ }^{(8,9)}$ Traditional ceramic fabrication techniques are multistep procedures and may produce restorations with different variabilities. Compared to the CAD/ CAM technique they are technique sensitive and time consuming. $\mathrm{CAD} /$ CAM ceramic fabrication technique may be a more reliable alternative for both the technicians and dentists. ${ }^{(18,19)} \mathrm{CAD} / \mathrm{CAM}$ ceramics are offered in the form of industrially fabricated dense homogenous blocks with less flaws and porosities. This leads to 
construction of restorations with optimal physical and mechanical properties compared to other ceramics. ${ }^{(20,21)}$ Dental ceramics are divided into three main families: resin-matrix ceramics, glass-matrix ceramics and polycrystalline ceramics (zirconiabased). The three types have representatives as CAD/CAM blocks. ${ }^{(22,23)}$

Hybrid ceramic combines resin resiliency with colour and strength of the ceramic materials. Vita Enamic is a commonly used fully sintered CAD/ CAM hybrid ceramic. It is a hybrid dental ceramic having a fully integrated dual network structure which consists of $86 \%$ wt. sintered fine structure ceramic network strengthened by $14 \%$ wt. acrylate polymer network filling and infiltrating the pores.

IPS e.max CAD lithium disilicate blocks contain $40 \%$ partially crystallized lithium metasilicate $\mathrm{LiSiO}_{3}$ in glassy matrix. Partial crystallization ensures that the blocks can be processed in a crystalline intermediate phase, which allows fast machining with the CAD/CAM milling systems. ${ }^{(24)}$

As claimed by the manufacturer, Celtra Duo is a zirconia reinforced lithium silicate ceramic that has a unique microstructure that contains $10 \%$ atomically dissolved zirconia incorporated in the glass matrix to provide high strength. Zirconia is responsible for the fine-grained lithium silicate crystals nucleation. The high glass content gives the material its excellent optical and mechanical properties as well as excellent polishability.

As wear measurement of restorative materials serve in prediction of restorations clinical longevity and performance. The aim of this research is to study wear and microhardness of the tested 3 ceramics representing three different types of ceramics: polymer-infiltrated ceramic, lithium disilicate ceramic and zirconia reinforced lithium silicate ceramic. The hypothesis of this research is that there will be a significant difference between the 3 tested ceramics as regards both the wear and microhardness with Celtra Duo will be the most abrasive material.

\section{MATERIALS \& METHODS}

\section{Samples preparations}

Thirty rectangular samples with dimensions 12 x 14 × $2 \mathrm{~mm}$ were constructed for the three tested ceramics [Vita Enamic (Vita Zahnfabrik, Bad Sackingen, Germany) which is a polymer-infiltrated ceramic, IPS e.max CAD (Ivoclar Vivadent AG, Schaan, Liechtenstein) which is a lithium disilicate reinforced ceramic, and Celtra Duo (Dentsply Sirona DeguDent GmbH. Germay) which is a zirconia reinforced lithium silicate ceramic)] to fit in the Teflon housing of the lower compartment of the chewing simulator. Each group consists of ten samples according to the type of ceramic material. Then, each group was subdivided into 2 subgroups (5 samples each). The first subgroups were subjected to microhardness test, while the second subgroups were first subjected to wear test, then to microhardness test. The samples were cut from the CAD/CAM blocks using a micro saw (Isomet 4000, Buehler, Illinois, USA). To ensure samples standardization, digital caliber (High-Accuracy Digimatic, Digital Micrometer, USA) was used to check the samples dimensions. Samples were then ultrasonically cleaned in distilled water for 10 minutes and air-dried using oil free compressed air and left for 24 hours to dry.

Vita Enamic samples were finished using the finishing diamonds using $50 \mu \mathrm{m}$ and $25 \mu \mathrm{m}$ impregnated grit drills (Komet, Brassler, German) and finally polished according to manufacturer recommendations using Vita Enamic polishing set/Technical (Vita Zahnfabrik, Bad Sackingen, Germany)

IPS e.max CAD samples were fired to be fully crystallized in a sintering furnace (Programat P500, Ivoclar Vivadent AG, Schaan, Liechtenstein) at $850^{\circ} \mathrm{C}$ for 30 minutes. Samples were then left to cool to room temperature. They were then finished using the finishing diamonds with $50 \mu \mathrm{m}$ and $25 \mu \mathrm{m}$ impregnated grit drills (Komet, Brassler, Germany) 
and finally using the OptraFine polishing system (Ivoclar Vivadent AG, Schann, Liechtenstein), the samples were polished.

The Celtra Duo samples were finished using the finishing diamonds with $50 \mu \mathrm{m}$ and $25 \mu \mathrm{m}$ impregnated grit drills (Komet, Brassler, Germany) and finally using the OptraFine polishing system (Ivoclar Vivadent AG, Schann, Liechtenstein). As per manufacturer instructions, Celtra Duo should be completely polished before firing if no glazing material is applied. Samples were subjected to firing cycles $\left(60^{\circ} \mathrm{C} / \mathrm{min}\right.$ heating rate, stand by temperature at $500^{\circ} \mathrm{C}$ and $820^{\circ} \mathrm{C}$ final firing temperature, $1 \mathrm{~min}$. holding time) in Programat P500 furnace (Ivoclar Vivadent AG, Schaan, Liechtenstein).

Samples of the second subgroups were weighed using high accurate four digital number scale with an accuracy of $0.0001 \mathrm{gm}$ (Sartorius, Biopharmaceutical and laboratories, Germany)

Fifteen caries free premolars extracted due to orthodontic or periodontal reasons (from patients between 18 to 30 years old) were used as antagonists in the study. Teeth were thoroughly washed, scaled and scrubbed to remove blood, plaque, calculus and remnants of the periodontal ligament. Only teeth with no obvious enamel defects were accepted. They were stored in Hanks' balanced salt solution (HBSS) (American Bioinnovations, LLC, Sparks, USA) to prevent enamel dehydration and maintain enamel hardness till use. ${ }^{(25)}$ The selected teeth were embedded in plastic cylinders filled with acrylic resin $1 \mathrm{~mm}$ above the CEJ, then sectioned vertically under copious amount of water, using a diamond saw (Isomet 1000, Buehler, IL, USA). Sectioning was done in a mesio distal direction separating the buccal cusps from the lingual ones then, using the same saw the lingual cusp was removed. Only the buccal cusps were used as antagonists to the ceramic samples in the chewing simulator. These samples were weighed using a the sensitive digital scale with four accuracy of $0.001 \mathrm{gm}$. Distance between the cusp tip and the base of resin blocks were measured using digimatic micrometer (HighAccuracy Digimatic, Digital Micrometer, USA).

\section{Wear test:}

Wear test was conducted using a chewing simulator (Robota- Ach-09075DC-T, AD-Tech Technology Co., Ltd., Germany). It has four chambers to perform vertical and horizontal movements. (Fig. 1) Each chamber has an upper Jackob's chuck for the tooth antagonist holder tightened with a screw and a lower plastic sample holder for ceramic samples embedded in a Teflon housing. A 33\% glycerin was used as a lubricant. The parameter of the wear test was: vertical movement $2 \mathrm{~mm}$, cycle frequency 1.6 Hz., horizontal movement $1 \mathrm{~mm}, 5 \mathrm{~kg}$ weight was exerted, 150000 cycles. ${ }^{(26-28)}$

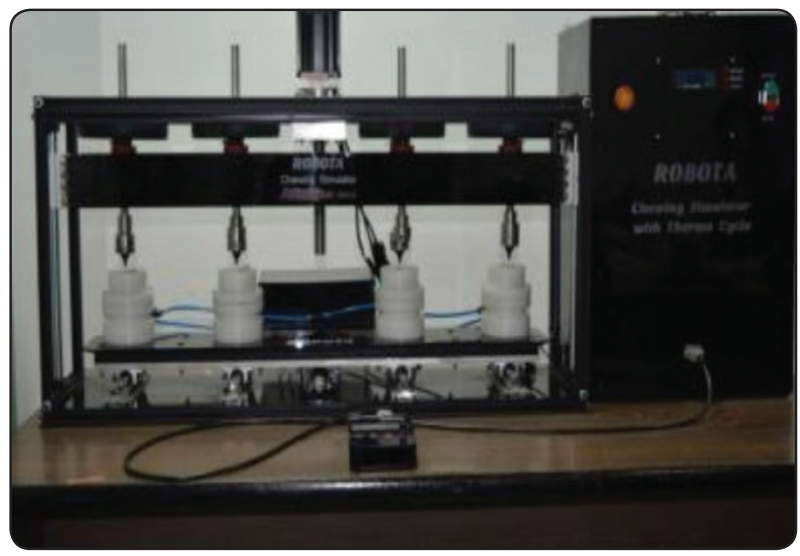

Fig (1): The chewing simulator

Ceramic samples and occlusal antagonists were re-weighed after the wear test and distance between the cusp tip and the base of resin blocks was remeasured.

\section{Microhardness Test:}

Samples of the first subgroups as well as samples of the second subgroups after being subjected to wear test were subjected to microhardness test. The surface hardness was measured using Vickers Hardness Tester (DVK-2, Matsuzawa Seiki Co., Japan). Each sample was mounted in the horizontal stage of the tester then the indenter was lowered at a loading speed $50 \mu \mathrm{m} / \mathrm{sec}$ under $10 \mathrm{Kg}$ for 20 seconds loading time. Indentations were measured immediately after automatic return of the indenter. Readings were performed by measuring the size of the diagonals of 
the indentation directly in Vickers. For each tested sample, 5 indentations were evaluated and an average hardness number was determined.(29)

\section{Statistical Analysis:}

All data obtained in this research were calculated, tabulated and statistically analyzed using one-way ANOVA Test. Then the Tukey test for multiple comparisons of means at $(p<0.05)$ was done.

\section{RESULTS}

Means and standard deviations of the wear test are represented in (Tables 1-3). A comparison between means is also represented in figures (2-4). A one way ANOVA Test was carried out to determine the statistical significant differences between the tested groups $(\mathrm{p}<0.05)$. The Tukey test at $(\mathrm{p}<0.05)$

TABLE (1) Weight loss of the tested ceramics due to wear in gm

\begin{tabular}{|c|c|c|c|}
\hline $\begin{array}{c}\text { Occlusal } \\
\text { antagonists }\end{array}$ & Enamic & $\begin{array}{c}\text { IPS e.max } \\
\text { CAD }\end{array}$ & Celtra Duo \\
\hline Means & $0.104^{\mathrm{a}}$ & $0.046^{\mathrm{b}}$ & $0.034^{\mathrm{b}}$ \\
\hline $\mathrm{SD}$ & 0.011 & 0.012 & 0.009 \\
\hline
\end{tabular}

Same letters denotes no significant difference

TABLE (2) Weight loss of the antagonist tooth structure due to wear in gm

\begin{tabular}{|c|c|c|c|}
\hline Ceramics & Enamic & $\begin{array}{c}\text { IPS e.max } \\
\text { CAD }\end{array}$ & Celtra Duo \\
\hline Means & $0.009^{\mathrm{a}}$ & $0.026^{\mathrm{b}}$ & $0.031^{\mathrm{b}}$ \\
\hline S.D. & 0.003 & 0.006 & 0.005 \\
\hline
\end{tabular}

Same letters denotes no significant difference was carried out following the one-way analysis of variance.

Concerning the weight loss of the tested ceramics, Vita Enamic recorded the highest weight loss (0.104 gm) while Celtra Duo recorded the least weight loss (0.034 gm). A significant difference was found between the weight loss of Vita Enamic and both IPS e.max CAD and Celtra Duo, while there was no significant difference between IPS e.max CAD and Celtra Duo. Table 1 and Figure 2

As regard weight and height loss of the occlusal tooth structure antagonist, Vita Enamic recorded the lowest weight loss $(0.009 \mathrm{gm})$ and the lowest height loss $(0.032 \mathrm{~mm})$. While against Celtra Duo, the occlusal antagonist recorded the highest weight loss $(0.031 \mathrm{gm})$ and the highest height loss $(0.113$ $\mathrm{mm})$. There was a significant difference between

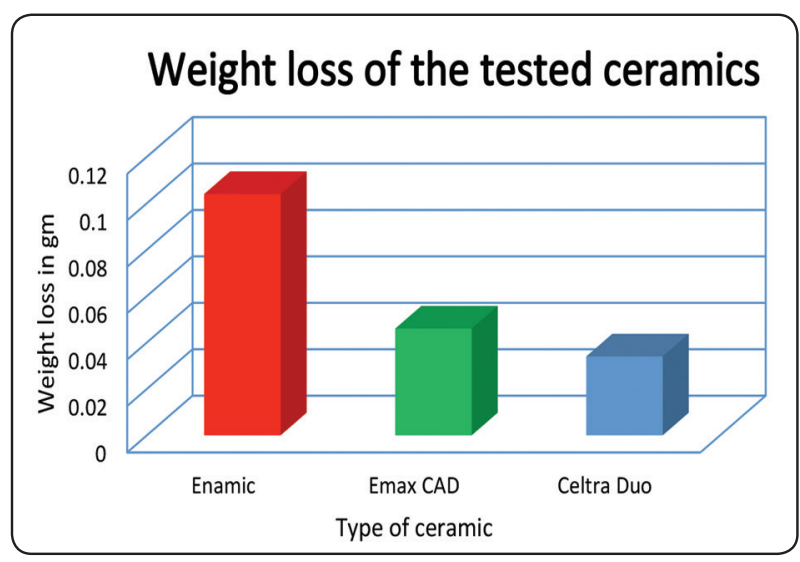

Fig. (2) Comparison between the weight loss of the tested ceramics

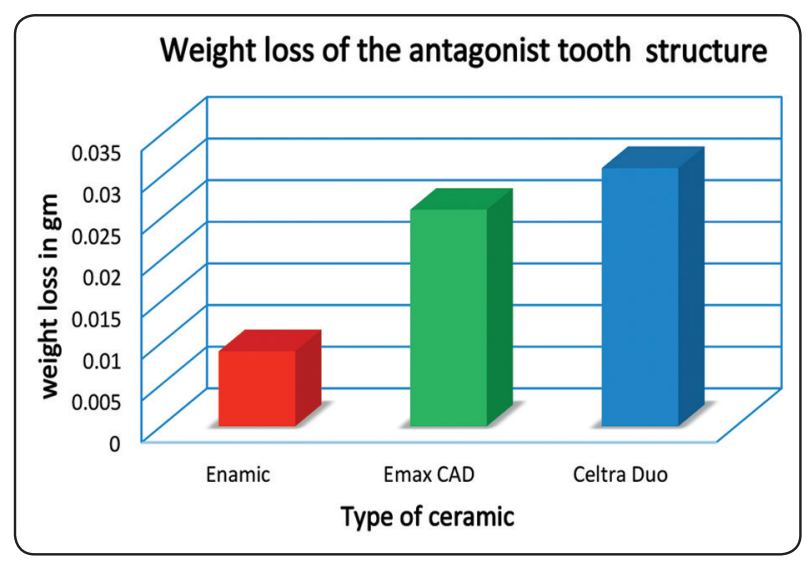

Fig. (3) Comparison between the weight loss of the antagonist tooth structure 
weight loss of the occlusal antagonist against Vita Enamic and against both IPS e.max CAD and Celtra Duo, while there was no statistically significant difference between weight loss of the occlusal antagonist against IPS e.max CAD and Celtra Duo. Table2 and Figure 3.

Also, there was a significant difference between height loss of the occlusal antagonist against Vita Enamic and against both IPS e.max CAD and Celtra Duo, while there was no significant difference between height loss of the occlusal antagonist against IPS e.max CAD and Celtra Duo Table 3 and Figure 4.

TABLE (3) Height loss due to wear in mm

\begin{tabular}{|c|c|c|c|}
\hline ceramics & Enamic & $\begin{array}{c}\text { IPS e.max } \\
\text { CAD }\end{array}$ & Celtra Duo \\
\hline Means & $0.032^{\mathrm{a}}$ & $0.098^{\mathrm{b}}$ & $0.113^{\mathrm{b}}$ \\
\hline SD & 0.005 & 0.009 & 0.009 \\
\hline
\end{tabular}

Same letters denotes no significant difference

\section{Microhardness:}

The means and standard deviations of the microhardness of the tested materials are represented in Table 4. A comparison between means is also represented in figure (5). One-way ANOVA Test was carried out to determine the statistical significant differences between the tested groups $(p<0.05)$. The Tukey test at $(\mathrm{p}<0.05)$ was carried out following the one-way analysis of variance. The results showed a statistically significant difference between Vita Enamic and both IPS e.max CAD and Celtra Duo. While there was no significant difference between IPS e.max CAD and Celtra Duo. Also, there was no significant difference for all the tested 3 ceramics between the control samples (without wear) and after wear test.

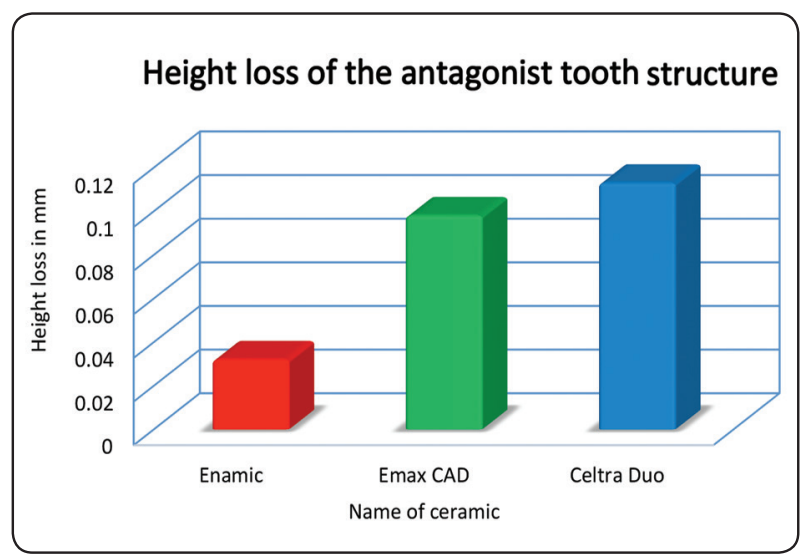

Fig. (4) Comparison between the height loss of the antagonist tooth structure

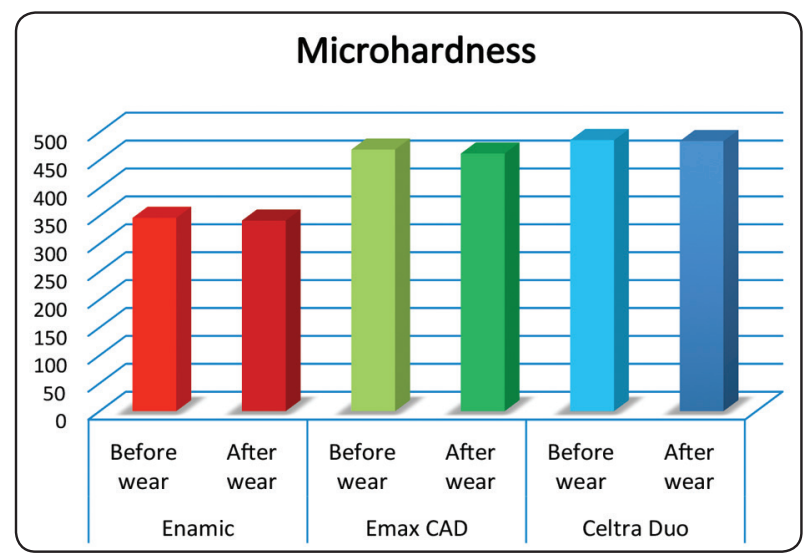

Fig (5) Comparison between the microhardness of the tested samples

TABLE (4) Means \& standard deviations of surface microhardness of the tested samples in VHN

\begin{tabular}{|c|c|c|c|c|c|c|}
\hline Ceramic & \multicolumn{2}{|c|}{ Enamic } & \multicolumn{2}{c|}{ IPS e.max CAD } & \multicolumn{2}{c|}{ Celtra Duo } \\
\hline Microhardness & $\begin{array}{c}\text { Without } \\
\text { wear }\end{array}$ & After wear & $\begin{array}{c}\text { Without } \\
\text { wear }\end{array}$ & After wear & $\begin{array}{c}\text { Without } \\
\text { wear }\end{array}$ & After wear \\
\hline Means & $346.321^{\mathrm{a}}$ & $341.568^{\mathrm{a}}$ & $468.734^{\mathrm{b}}$ & $461.657^{\mathrm{b}}$ & $485.674^{\mathrm{b}}$ & $483.854^{\mathrm{b}}$ \\
\hline Standard Deviations & $(6.245)$ & $(7.177)$ & $(8.956)$ & $(10.876)$ & $(7.761)$ & $(9.640)$ \\
\hline
\end{tabular}

Same letters denote no significant difference 


\section{DISCUSSION}

The current research studied the wear and microhardness of 3 types of available CAD/CAM ceramics against enamel antagonists. The three tested types were: Vita Enamic (polymer-infiltrated ceramic), IPS e.max CAD (lithium disilicate reinforced glass ceramic) and Celtra Duo (Zirconia reinforced lithium silicate ceramic). CAD/CAM blocks have the advantage that they are industrially produced to ensure standardization by neglecting the probability of processing defects. Several investigators reported that ceramic materials cause greater enamel wear compared with any other restorative materials. ${ }^{(30-32)}$ Although firing is optional for Celtra Duo, in this investigation firing was performed to allow the samples to reach their optimal mechanical properties.

Occlusal antagonists were upper first premolars extracted for orthodontic or periodontal reasons without modifying the buccal cusp tip. ${ }^{(33-35)}$ It was reported that extracted human enamel is more desirable for collecting information that may guide clinical practice. ${ }^{(36-38)}$ Also, studies that didn't use enamel and used ceramics instead as antagonist, ignored the fact that the enamel roughens during wear more than the ceramic thus affecting further wear and abrasiveness to the opposing. Teeth were stored in HBBS which has low affinity for dissolving calcium in tooth structure keeping minimal demineralization during storage time. ${ }^{(39)}$ Sectioning of teeth was done under copious amount of water to minimize the effect of generated heat, which might cause teeth dehydration and microstructural changes.

Several in-vivo and in-vitro wear behavior testing methods are developed to evaluate the occlusal wear of dental restorative materials. For standardizing all factors that may affect material wear, it seems that in-vitro tests are more beneficial and reliable. Clinical studies are time consuming, non-standardized and expensive. ${ }^{(40,41)}$ Also, in- vitro tests wear tests were conducted using wear simulators under controlled conditions; a pre-set load of $5 \mathrm{Kg}$ which is equivalent to $49 \mathrm{~N}$ representing the average physiological biting force in normal occlusion, 150000 cycles, representing one year of clinical use as described by Nawafleh et al (2016). ${ }^{(42)}$ Pre-determined adjustments as combination of vertically applied forces and lateral movement in order to simulate both abrasive and fatigue wear, in the presence of $33 \%$ glycerin as a lubricant for flushing away the abraded particles, making it two body instead of three body abrasion. ${ }_{(26,37,43,44)}$ Chewing rate used is $1.6 \mathrm{~Hz}$. as the recorded humans chewing rates are mostly below $2 \mathrm{~Hz}$. Although increasing the frequency can be very helpful to reduce the testing time but this may alter the results. ${ }^{(43)}$

Wear behavior was analyzed by measuring weight loss for the tested ceramics as well as measuring weight and height loss for the occlusal enamel antagonists. ${ }^{(40)}$ Also, Vickers Hardness Test is a convenient mean for investigating the mechanical properties of small volume materials. ${ }^{(45)}$

Vita Enamic recorded the highest weight loss followed by IPS e.max CAD then Celtra Duo. There was a significant difference between Vita Enamic weight loss and both IPS e.max CAD and Celtra Duo, while there was no significant difference between IPS e.max CAD and Celtra Duo weight loss.

Ceramic microhardness results for all groups showed no significant difference between without wear and after wear. However, a significant difference was found between Vita Enamic (the lowest microhardness) and the other two groups with no significant difference between IPS e.max CAD and Celtra Duo.

As the normal physiologic wear rate of mature enamel measured by Lambrechts et al (1989), ${ }^{(46)}$ reported the range of $29 \mu \mathrm{m}$ per year for molars and $15 \mu \mathrm{m}$ per year for premolars with an acceptable 
range of 20-40 $\mu \mathrm{m} /$ year for restorative materials. The results of the current study showed enamel wear exceeding this range per year. However, this may be attributed to that Lambrechts et al, carried out an in-vivo investigation with different environmental factors : exerting force, speed, lubrication, temperature and $\mathrm{pH}$.

Results come in accordance with researchers supporting that the lower the hardness of the restorative material the lower the enamel wear and vice versa. ${ }^{(47,48)}$ Also, with many researchers ${ }^{(49,50)}$ who proved that ceramics with higher crystallinity are much more wear resistant than ceramics with lower crystals content and consequently they are more abrasive to the opposing.

As for the Celtra Duo the dispersal of high $\mathrm{ZrO}_{2}$ content creates more nuclei for crystalline phase formation at lower energy input resulting in ultrafine microstructure with greater number of smaller crystallites (approx. 0.6-0.8 $\mu \mathrm{m}$ ). This microfine structure resulted in ceramic wear and enamel abrasion comparable to lithium disilicate ceramics.

Lawson et al (2016), ${ }^{(51)}$ performed Energy Dispersive $\mathrm{x}$-ray Spectroscopy (EDS) to examine the elemental composition of Celtra Duo and found no difference in the microstructure between the fired and unfired Celtra Duo. Analysis revealed disc-shaped crystals of lithium silicate and glassy matrix containing mainly oxygen, silica, and lithium with approximately $10 \%$ zirconia. Riquieria et al (2018), ${ }^{(52)}$ claimed that introduction of zirconia in to lithium disilicate acts as a stabilizer which restricts crystalline growth.

However, partially crystallized IPS e.max CAD blocks contain $40 \%$ lithium metasilicate platelet shaped crystals $\left(\mathrm{Li}_{2} \mathrm{SiO}_{3}\right)$ embedded in a glassy phase. Crystals size ranges between 0.2 to $1.0 \mu \mathrm{m}$. Which after thermal tempering and reaching final crystallization that reaches $70 \%$ fine-grain elongated spindle shaped lithium disilicate crystals $\mathrm{Li}_{2} \mathrm{Si}_{2} \mathrm{O}_{5}$ in glassy matrix.
Vita Enamic consists of $86 \%$ feldspar ceramic and $14 \%$ methacrylate polymer. It showed less wear resistance and less abrasiveness to the opposing enamel compared to the two other groups. This may be due to the presence of the weaker polymer infiltration as well as that glass ceramics used have a finer microstructure and more crystalline content compared to Vita Enamic. Also, asperities on the ceramic and enamel surfaces cause reciprocal abrasive scratching. ${ }^{(53)}$

While these results disagree with Mair et al (1996), ${ }^{(3)}$ Seghi et al(1991), ${ }^{(12)}$ Seghi et al (1995), ${ }^{(16)}$ and Lawson et al(2016) ${ }^{(51)}$ who reported no direct relationship between hardness and wear and claimed that roughness may exert a remarkable effect than does the hardness.

However, controversies existing about the relation between hardness and wear may be attributed to fact that wear is affected by many factors makes a direct relationship between microhardness and wear as well as comparable results of different researches difficult to attain.

The hypothesis in this study was partially accepted as there was a significant difference between Vita Enamic and both IPS e.max CAD and Celtra Duo, while there was no significant difference between IPS e.max CAD and Celtra Duo as regard both wear and microhardness.

\section{CONCLUSIONS}

1. Vita Enamic (polymer-infiltrated ceramic) showed the worst wear behavior and the least abrasiveness to enamel.

2. IPS e.max CAD (lithium disilicate ceramic) and Celtra Duo (Zirconia reinforced lithium silicate ceramic) showed comparable wear behavior and abrasiveness to enamel.

3. Ceramic microhardness is not affected by wear for the three tested ceramics. 
4. Ceramic microhardness although it is not the main factor affecting wear behaviour yet it may contribute in predicting the clinical behavior of the used ceramic.

\section{REFERENCES}

1. https://www.engineering-dictionary.com

2. Sakaguchi RL, Powers JM. Craig's restorative dental materials. Elsevier MOSBY Inc, St Louis. 2012; $13^{\text {th }}$.ed.

3. Mair L, Stolarski T, Vowles R, Lloyd C. Wear: mechanisms, manifestations and measurement. Report of a workshop. J Dent-1996; 24:141-148

4. Hahnel S, Schultz S, Trempler C,Ach B.Two-body wear of dental restorative materials. J Mech Behav Biomed Mater. 2011; 4:237-244.

5. Figueiredo-Pina CG, Monteiro A, Guedes M, Maurıcio, A, Serro, A P, Ramalho A, Santos C. Effect of feldspar porcelain coating upon the wear behavior of zirconia dental crowns. Wear. 2013; 297: 872-877.

6. D'Incau E, Couture C, Maureille B. Human tooth wear in the past and the present: Tribological mechanisms, scoring systems, dental and skeletal compensations. Arch Oral Biol. 2012; 57: 214-229.

7. Hutchings I M. Tibology: Friction and Wear of Engineering Materials. London, Butterworth-Heinemann Ltd.1992.1 ${ }^{\text {st }}$.ed.

8. Yip KH, Smales RJ, Kaidonis JA. Differential wear of teeth and restorative materials: clinical implications. Int $\mathrm{J}$ Prosthodont 2004; 17:350-6.

9. McIntyre F. Restoring esthetics and anterior guidance in worn anterior teeth: a conservative multidisciplinary approach. J Am Dent Assoc. 2000; 131:1279-1283.

10. Joshi N, Patil NP, Patil SB. The abrasive effect of a porcelain and a nickel-chromium alloy on the wear of human enamel and the influence of a carbonated beverage on the rate of wear. J Prosthodont, 2010; 19: 212-217.

11. Ramfjord SP, Ash MM. Occlusion, $3^{\text {rd }}$. ed. Saunders, Philadelphia 1983.

12. Seghi RR, Rosenstiel SF, Bauer P. Abrasion of human enamel by different dental ceramics in vitro. J Dent Res.1991; 70, 221-225.

13. Hudson J, Goldstein G. and Georgescu M. Enamel wear caused by three different restorative materials. J Prosthet Dent. 1995; 74:647-654.
14. Albakry M, Guazzato M. and Swain MV. Fracture toughness and hardness evaluation of three pressable allceramic dental materials. J Dent. 2003; 31:181-188.

15. Oh WS, Delong R, Anusavice KJ. Factors affecting enamel and ceramic wear: a literature review. J Prosthet Dent. 2002; 87:451-459.

16. Seghi RR, Denry IL, Rosenstiel SF: Relative fracture toughness and hardness of new dental ceramics. J Prosthet Dent. 1995; 74:145-150.

17. Zhang Y, Xu D, Rao P, Rao P, LÜ M. Friction behavior of dental porcelain with different leucite particle sizes. J Am Ceram Soc. 2008; 91:1678-1681.

18. Liu PR, Essig ME. Panorama of dental CAD/CAM restorative systems. Compend Contin Educ Dent. 2008; 29:482-488.

19. Miyazaki T, Nakamura T, Matsumura H, Ban S, KobayashimT. Current status of zirconia restoration. J Prosthodont Res. 2013; 57:236-261.

20. Hickel R, Manart J. Longevity of restorations in posterior teeth and reasons for failure. J Adhes Dent. 2001; 3:45-64.

21. Manhart J, Chen H, Hamm G, Hickel R. Buonocore Memorial Lecture. Review of the clinical survival of direct and indirect restorations in posterior teeth of the permanent dentition. Oper Dent. 2004; 29:481-508.

22. Li RW, Chow TW, Matinlinna JP. Ceramic dental biomaterials and CAD/CAM technology: State of the art. J Prosthodont Res. 2014; 58(4): 208-216.

23. Takaba M, Tanaka S, Ishiura I, Baba K. Implant-supported fixed dental prostheses with CAD/CAM-fabricated porcelain crown and zirconia-based framework. J Prosthodont. 2013; 22:402-407.

24. Scientific Documentation IPS e.max CAD Ivoclar Vivadent AG. Available from: http://www.ivoclarvivadent.

25. Sajewicz, E. On evaluation of wear resistance of tooth enamel and dental materials. Wear. 2006; 260:1256-1261.

26. Amer R, Kürklü D, Kateeb, E, Seghi RR. Three-body wear potential of dental yttrium-stabilized zirconia ceramic after grinding, polishing, and glazing treatments. J Prosthet Dent. 2014; 112:1151-1155.

27. D'Arcangelo C, Vanini L, Giuseppe D. Rondoni, De Angelis F. Wear properties of dental ceramics and porcelains compared with human enamel. J Prosthet Dent. 2016; 115:350-355 
28. Yasser O, Mohsen C, El-mahallawy O. Ceramic restorations worn against different occlusal antagonist (In vitro study). J Dent Med Sci. 2017; 16:87-92

29. Da Rocha SS, Adabo GL, Henriques GE, Nóbilo MA. Vickers hardness of cast commercially pure titanium and Ti-6Al-4V alloy submitted to heat treatments. Braz Dent J. 2006; 17(2): 126-129.

30. Lee A, Swain M, He L, Lyons K. Wear behavior of human enamel against lithium disilicate glass ceramic and type III gold. J Prosthet Dent 2014;112: 1399-405.

31. Tang X, Tang C, Su H, Luo H. The effects of repeated heatpressing on the mechanical properties and microstructure of IPS e.max Press. J Mech Behav Biomad Mater. 2014; 40:390-396.

32. Zhi L, Bortolotto T, Krejci I. Comparative in vitro wear resistance of $\mathrm{CAD} / \mathrm{CAM}$ composite resin and ceramic materials. J Proesthet Dent 2016; 115:199-202.

33. Bartlett D. A proposed system for screening tooth wear. $\mathrm{Br}$ Dent J. 2010;208(5): 207-209.

34. Amer R, Kürklü D, Johnston W. Effect of simulated mastication on the surface roughness of three ceramic systems. J Prosthet Dent.2015; 114(2):260-265.

35. Handa K, Murakami N, Yamazaki T, Takahashi H, Wakabayashi N. The ball-on-disk cyclic wear of CAD/ CAM machinable dental composite and ceramic materials. J Oral Sci. 2017; 59(4):589-596.

36. Kohyama K, Hatakeyama E, and Sasaki T. Effects of sample hardness on human chewing force: a model study using silicone rubber. Arch Oral Biol. 2004; 49: 805-816.

37. Preis V, Behr M, Handel G, Schneider-Feyrer S, Hahnel S, and Rosentritt, M. Wear performance of dental ceramics after grinding and polishing treatments. J Mech behav Biomed. 2012; 10:13-22.

38. Wang L, Liu Y, Si, W, Feng H, Tao Y, and Ma Z. Friction and wear behaviors of dental ceramics against natural tooth enamel. J Eur Ceram Soc. 2012; 32: 2599-606.

39. Habelitz S, Marshall Jr, GW, Balooch M, Marshall SJ Nanoindentation and storage of teeth. J Biomech.2002; 35, 995-998.

40. Albashaireh Z, Ghazal M, Kern M. Two-body wear of different ceramic materials opposed to zirconia ceramic. J Prosthet Dent; 104:105-13, 2010.
41. Mitov G, Heintze SD, Walz S, Woll K, Muecklich F, Pospiech P. Wear behavior of dental Y-TZP ceramic against natural enamel after different finishing procedures. Dent Mater; 2012; 28: 909-18.

42. Nawafleh N, Hatamleh M, Elshiyab S, Mack, F.: Lithium disilicate restorations fatigue testing parameters. A systematic review. J Prosthodont. 2016; 25: 116-26.

43. Heintze SD, Cavalleri A, Forjanic M, Zellweger G, Rousson V. Wear of ceramic and antagonist - a systematic evaluation of influencing factors in vitro. Dent Mater. 2008; 24(4):433-49.

44. Lawson NC, Janyavula S, Cakir D, Burgess JO. An analysis of the physiologic parameters of intraoral wear: a review. 2013; J Phys D Appl Phys. 2013; 46 (40): (9pp)

45. Mohsen C. Corrosion effect on the flexural strength and micro-hardness of IPS e-max ceramics. OJST. 2011; 1:29-35.

46. Lambrechts P, Braem M, Vuylsteke-Wauters M, Vanherle, G. Quantitative in vivo wear of human enamel. J Dent Res 1989; 68, 1752-1754.

47. Mörmann, Werner H, Bogna Stawarczyk, Andreas Ender, Beatrice Sener, Thomas Attin, Albert Mehl. Wear characteristics of current aesthetic dental restorative CAD/ CAM materials: two-body wear, gloss retention, roughness and Martens hardness. J Med behav Biomed Mater. 2013; 20: $113-125$.

48. Chun YL, Ngan AH, King NM. Nano-scale structure and mechanical properties of the human dentine-enamel junction. J Mech Behav Biomed Mater. 2011;4(5):785-795

49. Heintze SD. How to qualify and validate wear simulation devices and methods. Dent Mater 2006; 22(8): 712-734.

50. Lawson NC, Janyavula S, Syklawer S, McLaren EA, Burgess JO. Wear of enamel opposing zirconia and lithium disilicate after adjustment, polishing and glazing. J Dent. 2014; 42:1586-1591.

51. Lawson NC, Bansal R, Burgess JO. Wear, strength, modulus and hardness of CAD/CAM restorative materials. Dent Mater. 2016;32(11): e275-e283.

52. Riquieria H, Monteiro JB, Viegas DC, Campos TMB, de Melo RM, Saavedra GSFA. Impact of crystallization firing process on the microstructure and flexural strength of zirconia-reinforced lithium silicate glass-ceramics. Dent Mater. 2018; 34:1483-1491

53. Janyavula S, Lawson N, Cakir D, Beck P, Ramp LC, Burgess JO. The wear of polished and glazed zirconia against enamel. J Prosthet Dent 2013; 109:22-299. 